\title{
СМЕНА ПАРАДИГМЫ ТЕХНОЛОГИЧЕСКОГО РАЗВИТИЯ СОЦИАЛЬНО- ЭКОНОМИЧЕСКОЙ СИСТЕМЫ В УСЛОВИЯХ ЦИФРОВОЙ ТРАНСФОРМАЦИИ
}

\author{
(c) 2020 Погодина Татьяна Витальевна \\ доктор экономических наук, профессор департамента Менеджмента \\ Финансовый университет при Правительстве Российской Федерации, Россия, Москва \\ E-mail:pogodina15@yandex.ru \\ (c) 2020 Удальцова Наталья Леонидовна \\ кандидат экономических наук, доцент департамента Менеджмента \\ Финансовый университет при Правительстве Российской Федерации, Россия, Москва \\ E-mail: udaltsova.nl@yandex.ru
}

В статье выявлены основные тенденции, проблемы и перспективы технологического развития ведущих экономически развитых стран и России за 2005-2016 гг. Выделены тенденции постиндустриального способа производства и наиболее инновационно активные компании в каждом секторе экономики. Определены основные этапы смены технологических укладов в мировой экономике, выявлены процессы технологизации и их характерные черты. Доказано изменение роли технологий и превращение их в основной фактор развития социально-экономической системы. Выявлена прямая взаимосвязь между величиной и характером инвестирования и технологизацией развития. Сделан вывод о необходимости инвестирования в ключевые сектора технологического развития, которое активно развивается в странах Европы, Индии, Республике Корея, Японии, Китае и США.

Ключевые слова: технологический сектор экономики, уровень экономической добавленной стоимости страны, цифровая трансформация.

\section{Введение}

В современных условиях усиления международной конкуренции национальных экономик определяющими факторами конкурентоспособности выступают социальные, политические, технологические и коммуникационные аспекты развития стран и регионов. Уровень и качество большинства составляющих глобальной конкурентоспособности наций определяются научнотехническим потенциалом, в основе которого находится склонность экономических субъектов осуществлять деятельность в условиях постиндустриального способа производства. Ведущая роль в постиндустриальном технологическом укладе принадлежит новым технологиям, интеллектуальным ресурсам, характеру производства, капиталу, маркетингу и прочим элементам.

Постиндустриальная технологическая стадия развития рассматривается как особый технологический уклад, характеризующийся определенными особенностями. Во-первых, в постиндустриальной экономике технологии переходят из способа производства в движущий фактор и ресурс экономического роста, т.е. возникает новое явление - технологизация производства. Во-вторых, на макроуровне тех- нологизация экономики создает мультипликационный эффект, что выражается в приросте экономической добавленной стоимости. В-третьих, существенным образом расширяется сфера применения технологий, которая выходит за пределы производства и активно проявляется в процессах распределения, обмена и потребления. В-четвертых, результатом технологизации становится формирование наукоемкого производства. В-пятых, движущей силой технологизации становятся венчурные инвестиции, которые обладают мощным инновационным потенциалом, огромным резервом получения прибыли и обеспечения высокой рентабельность финансово-хозяйственной деятельности. B-шестых, эффект от венчурных инвестиций проявляется через достаточно долгий период времени - пять-шесть лет. Поэтому целесообразно внедрение стратегических подходов к осуществлению и оценке эффективности технологической трансформации.

В связи с вышеназванными особенностями, требуется более основательный и детальный подход к выявлению приоритетных направлений технологического развития экономики и оценке эффективности инвестирования. 


\section{Основная часть}

Мировая экономика находится в состоянии технологической трансформации, которая представляет собой двойственный процесс: с одной стороны, смены технологических способов производства и технологических укладов, с другой стороны, превращения технологии в базовый ресурс и движущую силу постиндустриального общества, приобретающий новое экономическое содержание. Мировая экономика в процессе своей эволюции последовательно осуществила переход от доиндустриального к индустриальному, а затем и постиндустриальному типу технологического уклада. Доиндустриальный технологический уклад базировался на использовании трудоемких технологий, индустриальный - на капиталоемких, а постиндустриальный - на наукоемких и цифровых технологиях. Особенностью современной мировой экономики является присутствие всех трех типов технологического уклада в различных странах. В то же время, лидирующее место в современном мире занимает постиндустриальная социально-экономическая система.

Использование инструментов цифровой экономики, нано- и биотехнологий способствует повышению инвестиционной привлекательности отраслей национальной экономики, поскольку открывает перед компаниями широкие перспективы повышения социальноэкономической эффективности за счет совершенствования управления производственными запасами, оптимизации послепродажного обслуживания реализуемых инновационных товаров, повышения производительности труда работников, активизации НИОКР. Технологизация, как самостоятельный и объективно реализующийся процесс экономического развития, обеспечивает гораздо более высокие темпы и качество экономического роста, поскольку в ее формировании ведущая роль принадлежит науке и технологиям. В то же время, технологизация увеличивает экономическое неравенство между отдельными странами и народами под воздействием различных факторов. Во-первых, существуют проблемы финансового обеспечения приобретения и реализации передовых производственных и информационных технологий. Во-вторых, имеют место кадровые и профессиональные ограничения в создании и ис- пользовании результатов постиндустриальной экономики. В-третьих, проявляются тенденции роста асимметричности информации под воздействием усиления роли транснациональных корпораций в мировой экономике. В-четвертых, ускоренная интеллектуализация производства обладает накопительным эффектом, заключающемся в концентрации интеллектуального капитала в отдельных странах и регионах $[1,9]$.

По нашему мнению, глобализация есть не что иное, как способ ускоренного технологического развития отдельных стран и регионов за счет поиска, отбора и привлечения интеллектуальных и технологических ресурсов по всему миру. Однако данному процессу предшествовала многовековая трансформация социально-экономических отношений. Динамика технологического развития и его основных характеристик в масштабе мировой экономики представлена на рисунке 1.

В целом, постиндустриальное технологическое развитие является интеграционным, учитывает достижения предыдущих технологических укладов. Результаты многочисленных исследований различных ученых показали, что в экономически развитых странах внедрение новых информационных и других передовых технологий дает в среднем 40-50\% экономического роста, капитала - 35-40\%, труда - 15-20\% $[2,12]$.

Технологизация - ключевая тенденция развития современной мировой экономики - представляет собой комплексный процесс эволюционного изменения роли технологий и превращения их в основной фактор производства. Можно выделить три уровня технологизации - низкий, средний и верхний. Верхний уровень определяется глобальным вектором развития, обуславливает восприятие принципиально новых технологий в мировом хозяйстве. Средний уровень технологизации аккумулируется на государственном уровне, включает совокупность мероприятий, соответствующих эволюционным закономерностям восходящего вектора технологического развития. Низкий уровень технологизации определяется коммерческой реализацией технологий. Объединение трех уровней технологизации можно рассматривать как наиболее желательный вектор ее реализации в мировом и национальном масштабах [3]. 


\begin{tabular}{|c|c|c|}
\hline \multicolumn{3}{|c|}{ Технологический уклад } \\
\hline Доиндустриальный & Индустриальный & Постиндустриальный \\
\hline \multicolumn{3}{|c|}{ Базовые ресурсы } \\
\hline Трудовые ресурсы & Физический капитал & $\begin{array}{c}\text { Интеллектуальные ресурсы, } \\
\text { технологии } \\
\end{array}$ \\
\hline \multicolumn{3}{|c|}{ Характер производства } \\
\hline Трудоемкий & Капиталоемкий & Наукоемкий \\
\hline \multicolumn{3}{|c|}{ Виды используемых технологий } \\
\hline $\begin{array}{c}\text { Технологии ручного труда, } \\
\text { мускульной энергии } \\
\text { животных, сил природы }\end{array}$ & $\begin{array}{c}\text { Технологии машинной } \\
\text { обработки, механизации } \\
\text { производства }\end{array}$ & $\begin{array}{c}\text { Информационно- } \\
\text { коммуникационные, нано- и } \\
\text { биотехнологии, технологии } \\
\text { генной инженерии } \\
\end{array}$ \\
\hline \multicolumn{3}{|c|}{ Способ достижения экономического роста } \\
\hline Экстенсивный & Интенсивный & Интеграционный \\
\hline \multicolumn{3}{|c|}{ Целевые экономические индикаторы } \\
\hline Совокупный продукт & Валовой внутренний продукт & $\begin{array}{c}\text { Экономическая добавленная } \\
\text { стоимость }\end{array}$ \\
\hline \multicolumn{3}{|c|}{ Целевые социальные индикаторы } \\
\hline $\begin{array}{c}\text { Удовлетворение базовых } \\
\text { потребностей }\end{array}$ & $\begin{array}{c}\text { Повышение уровня жизни } \\
\text { населения }\end{array}$ & $\begin{array}{c}\text { Повышение качества жизни } \\
\text { населения }\end{array}$ \\
\hline
\end{tabular}

Puc. 1. Тенденции и характеристики технологического развития мирового хозяйства Источник: разработано авторами

Рассмотрим основные индикаторы технологизации социально-экономических процессов в разрезе отдельных стран и представим результаты в таблице 1 .

Таким образом, пока страны ЕС, США и России осуществляют политические дискуссии, страны Азии взяли курс на технологизацию производства, правильно уловив главный тренд мирового развития. В 2005-2010 гг. мировое лидерство по показателям поступления патентных заявок в патентное ведомство страны лидирующие позиции занимали США. Однако, в 2016 г. ситуация изменилась и лидирующие позиции захватил Китай. По показателю доли стран в общем числе публикации в научных журналах, индексируемых в Web of Science, лидерство сохраняется пока еще за США, но Китай за 2006-2017 гг. продемонстрировал наивысший прирост - на 12,6\%, в то время как у лидера произошло снижение на 5,19\%. Лидерство по показателю доли внутренних затрат на исследования и разработки в ВВП принадлежит Республики Корея и в 2017 г. его значение составило 4,24\%.

Что касается России, то значение показателя поступления патентных заявок в патентное ведомство страны в 2016 г. составило 3,1\% к уровню Китая против 18,6\% в 2006 г. Доля внутренних затрат на исследования и разработки в процентах к ВВП в России выросла за 2006-2016 гг. на 0,03\% против 1,26\% в Республике Корея и 0,79\% в Китае. Следовательно, хотя Россия и демонстрирует положительную динамику по всем показателям, но в сравнении с другими быстро развивающимися странами значительно проигрывает 
Таблица 1. Тенденции технологизации социально-экономических процессов в отдельных странах в 2006-2016 гг.

\begin{tabular}{|c|c|c|c|c|c|}
\hline \multirow[b]{2}{*}{ Страны } & \multirow[b]{2}{*}{2005 г. } & \multirow[b]{2}{*}{2010 г. } & \multicolumn{3}{|c|}{2016 г. } \\
\hline & & & Факт & $\begin{array}{l}\text { уровень к ми- } \\
\text { ровому лидеру }\end{array}$ & $\begin{array}{c}\text { отклонение от } \\
2005 \text { г. }\end{array}$ \\
\hline \multicolumn{6}{|c|}{ Поступило патентных заявок в патентное ведомство страны, единиц } \\
\hline Россия & 32254 & 42500 & 41587 & 0,031 & 9333 \\
\hline Германия & 60222 & 59245 & 67899 & 0,051 & 7677 \\
\hline Великобритания & 27988 & 21929 & 22059 & 0,016 & -5929 \\
\hline Индия & 24382 & 39762 & 45057 & 0,034 & 20675 \\
\hline Республика Корея & 160921 & 170101 & 208830 & 0,156 & 47909 \\
\hline Китай & 173327 & 391177 & 1338503 & 1,000 & 1165176 \\
\hline Япония & 427078 & 344598 & 318381 & 0,238 & -108697 \\
\hline Канада & 39888 & 35449 & 34745 & 0,026 & -5143 \\
\hline США & 390733 & 490226 & 605571 & 0,452 & 214838 \\
\hline \multicolumn{6}{|c|}{ Доля стран в общем числе публикаций в научных журналах, индексируемых в Web of Science, проценты* } \\
\hline Россия & 1,90 & 2,21 & 2,32 & 0,091 & 0,42 \\
\hline Германия & 7,84 & 7,33 & 6,93 & 0,272 & $-0,91$ \\
\hline Великобритания & 8,16 & 7,74 & 7,72 & 0,303 & $-0,44$ \\
\hline Индия & 2,50 & 3,44 & 4,15 & 0,163 & 1,65 \\
\hline Республика Корея & 2,82 & 3,32 & 3,63 & 0,143 & 0,81 \\
\hline Китай & 8,63 & 11,17 & 21,19 & 0,833 & 12,56 \\
\hline Япония & 5,60 & 6,06 & 4,91 & 0,193 & $-0,69$ \\
\hline Канада & 4,29 & 4,57 & 4,35 & 0,171 & 0,06 \\
\hline США & 30,64 & 28,14 & 25,45 & 1,000 & $-5,19$ \\
\hline \multicolumn{6}{|c|}{ Доля внутренних затрат на исследования и разработки в ВВП, проценты } \\
\hline Россия & 1,07 & 1,13 & 1,10 & 0,259 & 0,03 \\
\hline Германия & 2,48 & 2,71 & 2,94 & 0,693 & 0,46 \\
\hline Великобритания & 1,76 & 1,67 & 1,69 & 0,399 & $-0,07$ \\
\hline Индия & $\ldots$ & 0,82 & 0,62 & 0,146 & $\ldots$ \\
\hline Республика Корея & 2,98 & 3,47 & 4,24 & 1,000 & 1,26 \\
\hline Китай & 1,33 & 1,71 & 2,12 & 0,500 & 0,79 \\
\hline Япония & 3,32 & 3,14 & 3,14 & 0,741 & $-0,18$ \\
\hline Канада & 2,01 & 1,83 & 1,60 & 0,377 & $-0,41$ \\
\hline США & 2,62 & 2,74 & 2,74 & 0,646 & 0,12 \\
\hline
\end{tabular}

*Данные приведены за 2006, 2010 и 2017 гг.

Источник: разработано авторами по данным Росстата [7]

и отставание усиливается. В некоторой степени данная тенденция характерна и для ведущих европейских стран.

В современных условиях технологическая трансформация мировой социальноэкономической системы осуществляется с учетом следующих тенденций. Во-первых, разные страны используют схожие стратегии технологического развития. Во-вторых, достижение конкурентных преимуществ реализуется не на основе национальной обособленности страны, а с учетом преимуществ от интернационализации научных исследований и разработок. В-третьих, технологическая трансформация приводит к росту благосостояния и качества жизни населения $[2,10]$.

В связи с этим, процесс технологизации в российской социально-экономической системе должен соответствовать этим тенденциям и обеспечивать стране конкурентные преимущества путем интеграции в глобальное научно-технологическое пространство. Наиболее значимыми стратегическими направлениями технологизации национальной экономики 
должны стать повышение ресурсной эффективности, технологической восприимчивости и инновационности. Целевой индикатор - максимизация приращения экономической добавленной стоимости в стране (EVAc).

Традиционно для отдельно взятой компании экономическая добавленная стоимость считается по следующей формуле:

EVA = IC x (ROIC - WACC)

Где IC - капиталовложения;

ROIC - рентабельность инвестируемого капитала;

WACC - средневзвешенная стоимость капитала.

С учетом особенностей национальной экономики экономическая добавленная стоимость по стране может считаться следующим образом:

$\mathrm{EVAc}=\mathrm{IC} \times(\mathrm{ROA}-\mathrm{CC})$

Где IC - валовое накопление основного капитала;

ROA - рентабельность активов;

CC - стоимость капитала.

Показатель экономической добавленной стоимости страны отражает эффективность инвестиционной деятельности на макроуровне. Данный показатель может иметь положительное, нулевое или отрицательное значение.

На макроуровне целесообразно рассчитывать уровень экономической добавленной стоимости по следующей формуле:

YEVAc $=$ YIC $(\mathrm{ROA}-\mathrm{CC})$

Где YIC - доля накопления основного капитала в ВВП;

YEVAc - уровень экономической добавленной стоимости.

Проведем анализ эффективности инвестирования и технологизации социально-экономи- ческой системы на основе расчета уровня экономической добавленной стоимости в России и отдельных странах мира и представим результаты в таблице 2 .

Таким образом, наивысшие показатели уровня экономической добавленной стоимости в 2014 г. были у Республики Корея - 9,18\%. Высокие показатели уровня экономической добавленной стоимости (более 6\%) также отмечены в Японии, Канаде и США. Пониженные уровни экономической добавленной стоимости (менее $4 \%)$ отмечены во Франции и России. В России основной проблемой низкого уровня экономической добавленной стоимости является высокая стоимость капитала, которая значительно выше в сравнении с другими странами. Отсюда вытекающие проблемы, связанные с недостаточными венчурным инвестированием и технологизацией развития [11, 14].

Следовательно, уровень экономической добавленной стоимости неразрывно связан с инновационной направленностью инвестиций и технологизацией социально-экономической системы. Страны, которые расширяют венчурное инвестирование, стимулируют технологизацию развития, имеют значительно более высокий уровень экономической добавленной стоимости.

\section{Заключение}

Для ускоренного развития технологического сектора экономики России необходимо сделать акцент на передовых технологиях, выступающих главным ресурсом формирования постиндустриальной экономики. Технология как ресурс составляет основу экономической системы и ее использование выводится за пределы собственно производственной сферы. Следует отметить изменение роли технологий в экономическом

Таблица 2. Сравнительный анализ экономической добавленной стоимости по отдельным странам в 2014 г., проценты

\begin{tabular}{|l|c|c|c|c|c|}
\hline \multicolumn{1}{|c|}{ Страны } & YIC & ROA & CC & $\begin{array}{c}\text { Экономиче- } \\
\text { ский диффе- } \\
\text { ренциал }\end{array}$ & УEVAc \\
\hline Россия & 20,1 & 30,0 & 11,14 & 18,86 & 3,79 \\
\hline Германия & 19,0 & 29,3 & 4,95 & 24,35 & 4,63 \\
\hline Великобритания & 17,8 & 24,7 & 0,50 & 24,2 & 4,30 \\
\hline Франция & 22,2 & 20,6 & 6,07 & 14,53 & 3,22 \\
\hline Республика Корея & 29,3 & 35,5 & 4,26 & 31,24 & 9,18 \\
\hline Япония & 21,8 & 31,7 & 1,22 & 30,58 & 6,67 \\
\hline Канада & 24,2 & 28,2 & 3,00 & 25,2 & 6,09 \\
\hline СшА & 19,9 & 34,1 & 3,25 & 30,85 & 6,13 \\
\hline
\end{tabular}

Источник: рассчитано авторами по данным Росстата [7] 
развитии общества, которая проявляется в том, что новые технологии становятся не причиной, а следствием возникновения новых потребностей. Технология в постиндустриальном обществе получает новое экономическое содержание, характеризующееся технологизацией производственных процессов.

В то же время, в российской экономике на сегодняшний день отсутствуют принципиальные сдвиги в структуре и качестве технологического капитала. Это порождает необходимость разработки стратегии технологического развития российской экономики в рамках реализации политики технологической модернизации. Данный процесс необходимо начинать на государственном уровне с фундаментальных исследований и прорывных технологий, участия страны в международных программах и реформирования инновационной инфраструктуры. В дальнейшем целесообразно формирование планов технологического развития, связанных с разработкой прикладных исследований. Немаловажную роль играет также оценка эффективности и коммерческой реализуемости реальных технологических продуктов и технологических процессов.

Для масштабной и системной реализации процессов технологической трансформации нужны специалисты «новых» профессий в области креативной и цифровой экономики, восстановления экологии, человекоориентированных сервисов и др. Интегрироваться в новые профессиональные стандарты смогут только люди с хорошо развитым экологическим мышлением, высокой цифровой грамотностью, способные переобучаться. Для формирования и развития подобных навыков необходимы: изменения в системе обучения на всех его уровнях; интеграция российской системы образования в глобальную; развитие производственных и инновационных площадок, на которых возможна практическая реализация студентами полученных в аудиториях знаний.

Таким образом, смена парадигмы технологического развития заключается в становлении постиндустриального технологического уклада на основе извлечения дополнительных выгод от международного сотрудничества между национальными социально-экономическими системами.

\section{Библиографический список}

1. Зотова И.В. Креативность как драйвер экономики XXI века // Экономика. Бизнес. Банки. Т. 1 М.: Изд- во РИМ.- 2017.- С. 101-120.

2. Иванова Е.В. Технологический капитал - теория и практика эволюционных изменений: монография.- М.: Изд-во МГСУ, 2008.- 274 с.

3. Иванова Е.В. Инвестиционные возможности технологического развития российской экономики// Вестник университета. - 2009. - № 12.- С. 16-21.

4. Национальная инновационная система и государственная инновационная политика Российской Федерации. Базовый доклад к обзору ОЭСР национальной инновационной системы Российской Федерации [Электронный ресурс].- Режим доступа: http://mon.gov.ru/files/materials/6333/09.11.11-bd-rus.pdf

5. Новиков A. Особенности IR-практики российского эмитента в Китае и других странах ATP.- Режим доступа: http://www.ir-russia.ru/news/novikov-ir-specifics-for-russian-comanies-in-asia-20150330/

6. Обзор рынка венчурной индустрии России за 2016 год // Моney Tree. Навигатор венчурного рынка / ОАО «РВК» [Электронный ресурс].- Режим доступа: http://www.rvc.ru/upload/iblock/905/money-tree-rus-2016.pdf

7. Российский статистический ежегодник. Росстат. [Электронный ресурс]. - Режим доступа: http://www.gks.ru

8. Топ «Инновационные» рейтинга «Техуспех» - 2016 [Электронный ресурс].- Режим доступа: http://www. ratingtechup.ru/rate/? BY=INNOVATION

9. Borodin A. I., Ziyadin S., Streltsova E., Kiseleva N., Yakovenko I. and Baimukhanbetova E. Assessment of Investment Attractiveness of Projects on the Basis of Environmental Factors // Sustainability. - 2019. -11 (9). -pp. 1-16.

10. Gubernatorov A.M., Kornilova o.A., Popadyuk T.G. Financing of innovative development of the textile industry / Izvestya Vysshikh Uchebonykh Zavedenii, Sriya Teknologiya Tekstil'noi Promyshlennosti - 2018. - 370 (4).pp.170-21.

11. Pogodina, T.V., Muzhzhavleva, T.V., Udaltsova, N.L. Characteristics of venture capital investing in a climate of the digitalization of the Russian economy // International Journal of Civil Engineering and Technology. - 2018.9(10). - pp. 698-706.

12. Solvell O., Lindqvist G., Ketels Ch. The Cluster Initiative Greenbook. The Competitiveness Institute/VINNOVA, Gothenburg, 2003. 
13. Streltsova E., Borodin A.I., Yakovenko I., Sokira T., Bizhanova K. Information management system of industrial enterprise in conditions of digitalization // International Journal of Civil Engineering and Technology - 201910(1). -pp. 559-575.

14. Trachuk. A. Linder N. Innovation and Performance: An Empirical Study of Russian Industrial Companies // International Journal of Innovation and Technology Management - 2018-15 (3). 